\title{
Case Report on Patent Ductus Arteriosus with Eisenmenger Syndrome
}

\author{
Doody Thomas*, Neha Maria Augustine, Abhirami Azad, Femy Thomas, Midhuna Saju \\ Department of Pharmacy Practice, Nirmala College of Pharmacy, Nirmala Hills, Muvattupuzha P.O, Ernakulam, Kerala, INDIA.
}

\begin{abstract}
Eisenmenger Syndrome (ES) is a rare progressive heart condition characterized by structural abnormalities of the heart with abnormal blood circulation due to arterioventricular canal defect, Patent Ductus Arteriosus (PDA), atrial septal defect, etc. Untreated patent ductus arteriosus can lead to Eisenmenger syndrome. A 40-year-old female patient was admitted with chief complaints of shortness of breath, chest pain, and insomnia. Her past medical history revealed a rare case of PDA with Eisenmenger Syndrome, severe supra systemic pulmonary arterial hypertension (PAH), and biventricular failure. Elevated $\mathrm{Hb}$ level and on physical examination P2 sound was loud. ECG obtained and the report was abnormal, which shows right and left atrial enlargement, incomplete right bundle branch block, RV and LV hypertrophy, ST deviation and moderate $\mathrm{T}$ wave abnormality reports manifested right and left heart failure. Treatment was carried out with diuretics, antibiotics along with her past medications.
\end{abstract}

Key words: Eisenmenger syndrome, Patent ductus arteriosus, Pulmonary arterial hypertension, Biventricular failure, Hypertrophy.

\section{INTRODUCTION}

Patent Ductus Arteriosus (PDA) is a lifethreatening congenital heart defect in which the ductus arteriosus fails to spontaneously close after birth. It is the most common type of extra cardiac shunt which accounts for $10-12 \%$ of congenital heart diseases in adults and has an elevated incidence rate in the female population. Incidence of this condition is about 6 per 10,000 in full-term infants and 1 per 3 in preterm infants. Untreated PDA finally leads to Eisenmenger syndrome. ${ }^{1,2}$ Eisenmenger syndrome is a rare progressive heart condition characterized by structural malformations of the heart with abnormal blood circulation on behalf of heart defect like atrioventricular canal defect, Patent ductus arteriosus, Atrial septal defect, Cyanotic heart disease etc. which are existing from birth. This syndrome begins to develop before puberty. Eisenmenger syndrome was initially described in 1897 when Victor Eisenmenger reported on a patient with dyspnea and cyanosis from infancy and later it evolved into heart failure and succumbed to massive hemoptysis. ${ }^{3}$ he incidence of ES is 1 -9 out of 10 lakh. The overall prevalence has declined as a sequel to advanced diagnostic and therapeutic measures. The majority of symptoms develop during infancy, as pulmonary obstruction increases, right to left shunting increase and eventually patient become symptomatic with dyspnea and exercise intolerance. Cyanosis progresses, erythrocytosis and hyperviscosity become remarkable problems. The physical examination of ES is mainly cyanosis and digital clubbing in proportion to the enormity of right to left shunt. The onset of pulmonary hemorrhage is the indicator of the rapid progression of this disease. ${ }^{1,4}$

\section{CASE REPORT}

A 40-year-old female patient weighing $70 \mathrm{~kg}$ was presented to the emergency department
DOI: 10.5530/ijopp.14.4.60

Address for correspondence: Dr. Doody Thomas, Pharm.D Intern, Nirmala College of Pharmacy, Nirmala Hills, Muvattupuzha P.O, Ernakulam-686661, Kerala, INDIA.

Phone no: +91-7559814721 Email id: doodytk252@gmail. com

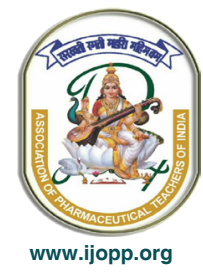


unit of the hospital. She was complaining of shortness of breath, chest pain, and insomnia. Further inquiry into her past medical history revealed a rare case of PDA with Eisenmenger Syndrome, severe supra systemic pulmonary arterial hypertension, and biventricular failure. Her medication history encompasses spironolactone and furosemide combination, sildenafil $50 \mathrm{mg}$ and ambrisentan $5 \mathrm{mg}$. During vital signs scrutiny patient was afebrile and oriented, blood pressure was found to be $140 / 90$ on the day of admission and laboratory investigation, her hemoglobin ( $\mathrm{Hb}$ ) value was $17 \mathrm{gm} \%$ and it was monitored only during the admission time. On RFT and LFT monitoring, the hepatic and renal function was found to be normal. On systemic examination, S1 and S2 sound was heard and the P2 sound was loud which usually arises in atrial septal defect without pulmonary hypertension and pulmonary hypertension. ECG obtained and the report was abnormal, which shows right and left atrial enlargement, incomplete right bundle branch block, RV and LV hypertrophy, STdeviation, and moderate $\mathrm{T}$ wave abnormality. She was diagnosed with right and left heart failure along with Eisenmenger Syndrome.

\section{Treatment given}

The desired outcome was rehabilitation and treatment was initiated with diuretics, Furosemide $20 \mathrm{mg}$ intravenously thrice a day (t.i.d) for 3 days and Spironolactone $25 \mathrm{mg}$ orally twice a day for heart failure. The patient was also administered with proton pump inhibitor pantoprazole $40 \mathrm{mg}$ intravenously twice a day for gastrointestinal disturbances and antibiotic ceftriaxone $1 \mathrm{gm}$ twice a day intravenously to prevent hospital- acquired infections along with her past medication Ambrisentan $(5 \mathrm{mg})$ and sildenafil $(50 \mathrm{mg})$. After 3 days, the patient- reported pain relief and was discharged with her past medications.

\section{DISCUSSION}

Eisenmenger syndrome is mainly caused due to congenital heart disease including ventricular septal defects, atrial septal defects, and patent ductus arteriosus. This generally develops in children before puberty and infants with large ventricular septal defect or a persistently arterial duct are most susceptible. Although the patients with ES survive for decades of life, the symptoms of this disease include cyanosis, dyspnea, fatigue short survival period, as well as a late complication of ES is a frequent cause of sudden death in patients with ES. ${ }^{5,6}$

Clinical management of ES mainly focused on palliative and supportive care. Treatment mainly consists of diuretics, anticoagulants, maintaining fluid balance, and prophylaxis against infective endocarditis, iron supplementation, and avoiding precipitating factors like pregnancy, high altitude, etc. along with supplemental oxygen and phlebotomy also proved to be beneficial. To date, the only definitive treatment is lung or heart transplantation. The best possible way to control ES by appropriate repair of the underlying heart defect before the establishment of irreversible changes to the pulmonary vascular bed. In this case, the patient is a well-known case of ES and was educated patient about diet, weight reduction, and the importance of dental hygiene. The patient's chest pain was managed with diuretics along with her past medications. Hb level was monitored only the day of admission and further evaluation is not carried out. Phlebotomy can be carried out to manage higher $\mathrm{Hb}$ and she past medication sildenafil for PAH was an overdose and its maximum dose was $50 \mathrm{mg}$ OD. Following therapy, the patient-reported pain relief and was discharged. The patient was informed about the recurrence of these events and insisted to adhere to regular medications.

\section{CONCLUSION}

Eisenmenger syndrome is a multisystem disorder that is correlated with a multitude of complications and reduced life expectancy. Patients with ES may be asymptomatic for prolonged period's results in a delay in diagnosis. The usual life expectancy of a patient with ES is $20-40$ years if the syndrome is diagnosed and managed with attention. The mortality of ES also rises dramatically during the $5^{\text {th }}$ decade of life. The mean age of death in patients with ES is 37 years. Cardiac arrhythmias and sudden cardiac death are the delayed complications of this syndrome. Studies show that prognosis depends on the magnitude of PDA and the degree of shunting. Prevention of this syndrome is critical. Early diagnosis and surgical method should be executed in patients with congenital heart disease to prevent progression to Eisenmenger syndrome is the final remedy.

\section{ACKNOWLEDGEMENT}

We are thankful to Management, Pharmacy Practice Department, and Principal of Nirmala College of Pharmacy for providing necessary facilities and support.

\section{CONFLICT OF INTEREST}

The authors declare no conflict of interest. 


\section{ABBREVIATIONS}

ED: Eisenmenger syndrome; PDA: Patent ductus arteriosus; PAH: Pulmonary arterial hypertension.

\section{REFERENCES}

1. Kaemmerer H, Mebus S, Schulze-Neick I, Eicken A, Trindade PT, Hager A, Oechslin E, Niwa K, Lang I, Hess J. The adult patient with Eisenmenger syndrome: a medical update after Dana Point part I: Epidemiology, clinical aspects and diagnosticoptions. Curr Cardiol Rev. 2010;6(4):343-55. doi: 10.2174/157340310793566154, PMID 22043211.
2. Dice JE, Bhatia J. Patent ductus arteriosus: an overview. J Pediatr Pharmacol Ther. 2007;12(3):138-46. doi: 10.5863/1551-6776-12.3.138, PMID 23055849.

3. Wood $\mathrm{P}$. The Eisenmenger syndrome or pulmonary hypertension with reversed central shunt. Br Med J. 1958 Sep 27;2(5099):755-62. doi: 10.1136/ bmj.2.5099.755, PMID 13572894.

4. Penalver J. Eisenmenger syndrome. emedicine. Available from: http:// medscape.com/article/154555-overview [cited 20/7/2021].

5. Sørensen Hjortshøj CM, Kempny A, Jensen AS, et al. Past and current causespecific mortality in Eisenmenger syndrome. European Society of Cardiology; 2017; 38(26). p. 2060-7.

6. Moceri P, Kempny A, Liodakis E, Alonso Gonzales R, Germanakis I, Diller GP, Swan L, Marino PS, Wort SJ, Babu-Narayan SV, Ferrari E, Gatzoulis MA, Li W, Dimopoulos K. Physiological differences between various types of Eisenmenger syndrome and relation to outcome. Int J Cardiol. 2015 Jan 20;179:455-60. doi: 10.1016/j.ijcard.2014.11.100, PMID 25465305. 